\title{
Assessment of Socio Cultural Factors Affecting the Utilization of Family Planning Services: The Case of Haramaya town Bate Kebele
}

\author{
Selam Mera \\ Haramaya University, Haramaya, Ethiopia \\ Department of Sociology
}

\begin{abstract}
In Ethiopia socio cultural factors are highly determine the utilization of family planning services. There are many socio cultural factors that contributes to low contraceptive use, high fertility rate, un meet need of family planning services among these: religion, culture, misconception and social norm as a barriers to universal untaken of contraceptive use in Ethiopia. The objective of the study was to assess socio cultural factors affecting the utilization of family planning services: The case of Haramaya town Bate kebele.This study was used different research methodology like, cross-sectional studies, with in research approach, the study was used mixed research approach, and also the study was obtained information from primary and secondary data sources. In addition to this, study was employed Interview and Survey methods. The study was used non-probability sampling techniques, with these techniques particularly purposive (Judgmental), and through this technique the researcher was selected 98 samples and also the researcher was analyzed the qualitative and quantitative data, that get from interview and questionnaire through narration, percentages and frequency. The Findings of this study was religious fundamentalists who are not take family planning services, and also they condemned individuals who used family planning services and Culture give much value to children. Family planning challenged by tradition it means the mainstream culture toward family planning, society perception, society perceive the concept family planning in a negative sense, it lead to imbalance of ministration, sterilization, over fatty and other negative explanation are given to the services. Both governmental and non-governmental health care institutions should strongly attach each other for the mitigating of socio-cultural factors affecting on family planning services utilization.
\end{abstract}

Key words: Culture, Contraceptive use, Family planning

DOI: $10.7176 /$ RHSS/9-21-06

Publication date: November $30^{\text {th }} 2019$

\section{INTRODUCTION}

As worldwide efforts to address issue of development and income inequality, family planning program have come in to focus. Particularly in a nation where rapid population growth threatens economic stability and health outcome. Family planning services is an educational, comprehensive medical or social activity which enables individuals to determine freely the number and spacing of their children and to select how this may be achieved (Cleland J. et al , 2006). When a nation are able to stabilized there population growth, maternal and infant mortality rate decreases, enabling women to pursue education and occupation. Collectively the results as generated by the behavior of family planning promote the welfare of individuals, families, communities, and nation. Family planning is one of the highly advocated options in developing countries to control the fast population growth and to decrease the higher maternal and child deaths though it has steadily decreased as an international priority in recent years (Gorden C. et al, 2011).

Sub-Sahara African countries as a region have struggled with implementation of family planning program. In the developing country, an estimated 137 million women who want to avoid a pregnancy are not using a family planning method (Smith R. et al, 2009). Sub-Saharan African countries are experiences high fertility rate in the world with average of 5.4 children born peer women (USAID, 2008). Unrestricted population growth is a core of the religion, history that affected economic development. In Africa 18\% of the married women's use a modern contraceptive method of family planning (USAID, 2009). Ethiopia is one of the sub-Sahara African countries, high fertility rate and low contraceptive is mostly common. The population has estimated above 90 million, making it is a second populated country in sub Saharan African (Yohanes and Girma, 2011). The country experience as proximate population growth is $3.2 \%$ and average number of born children per women is $6.2 \%$ (CSA, 2006). In Ethiopia also high maternal mortality rate, and high unmetered of family planning services is existed just $13.9 \%$ reports, use modern contraceptive methods (Woldegerima and Denekew, 2008).

In developing country like Ethiopia birth control get priority and many programs have been implemented by Ethiopian government policy since 1993 to increase a contraceptive practices. However, the problem of high fertility rate and low contraceptive practices are still present. So the existence of these problems that affecting family planning services utilization, there are many researchers like (Bekele A., 2006) conducted and analysis of 
socio cultural factors on family planning the whole only quantitatively and also Tilahun W. and Kassahun T., (2013) conducted researches regarding to socio cultural factors affecting family planning services but they are focused only married women's. So in this study both women's and a man's who are within marriage from the target population will considered. Fasil Haile Georgis (2006), conducted research on attitude and knowledge on family planning senses. But behind respondent's attitude and knowledge there are socio-cultural rooted problems of family planning species utilization, therefore, this study is focused on socio-cultural factors behind their attitude and knowledge for specific target area. So this research will focused to address other places like Bate kebele and to give information regarding to factors affecting family planning services utilization.

General Objective

The general objective of this study was to investigate the socio cultural factors affecting the utilization of family planning services in Haramaya town Bate kebele.

Specific Objectives

$>$ To indentified the socio-cultural factors affecting family planning services utilization.

$>$ To examined the participants towards the utilization of family planning services

\section{Research Methodologies}

\subsection{Research Design}

The study was used cross-sectional studies due to shortage of time and the data collected from study participants at one point of time. The researcher was smooth relationship with respondents and clearly discuss about the aim of the study to get more accurate and reliable data with in that short period of time.

\subsection{Research Approach}

The study was employ mixed research approach, to understand the thought, perception and believes of study participants (both married men and women) and to express in a summarization and narrative way by qualitative approach and also to investigate systematically on acts, effects, cause and consequence and it magnitudes quantitative approach used.

\subsection{Source of Data}

The study was done to obtaining information from two data sources, primary data and secondary data sources. Primary data sources were obtained from study participants (married women and men) through interview and survey methods; by preparing interview questionnaires therefore, first-hand information obtains from study participants. Secondary data was taken from books, journals and other unpublished literatures that related to the subject matter of the study topic.

\subsection{Methods and Tools of Data Collection}

The study based on both qualitative and quantitative methods. In qualitative research methods, the study was done by used interview method. Structured questionnaire was employed in order to generate the relevant information from study participants by the preparing of interview guideline. With quantitative research methods, the researcher was also employed survey method.

\subsection{Sample and Sampling Techniques}

In this study, systematic random sampling technique, particularly purposive (Judgmental) sampling technique, as the target population of the study focuses both on married women and men couple's. The researcher selecting $\mathbf{n}$ samples of target respondents of married women and men from the total population (N) of bate Keble by using the following sampling size.

$\mathrm{n}=\mathrm{N} / 1+\mathrm{Ne}^{2}$ Where;

$\begin{array}{lc}\mathrm{N}=3930 & \mathrm{n}=3930 / 1+3930(0.01) \\ \mathrm{E}=10 & \mathrm{n}=98 \\ \mathrm{CI}=90 & \end{array}$

\subsection{Method of Data Analysis}

Analyzing data was obtained from respondents through qualitative and quantitative methods. The qualitative data obtain through interview method. But, the quantitative data that obtaining through survey method was analyzed by table, percent, and frequency.

\section{Data Presentation and Analysis}

As clearly stated in the statement of the problem the main concern of the study was to assess the socio-cultural factors affecting the utilization of family planning services: The case of Haramaya town Bate kebele. This part of the paper includes the data which were gathered through semi structured interview and self-administrative 
questionnaire from selected 98 respondents in Bate kebele out of 3930 married individuals ( May, 2007 G.C Population and Housing Census of Ethiopia: Statistical Report for Oromiya Region” for the users).

\subsection{Background Information of Respondents}

Table 3.1. Background Information of Respondents

\begin{tabular}{|l|l|l|l|}
\hline Items & Variables & In number (frequency) & In percent \% \\
\hline Sex & female & 52 & 53.06 \\
\hline & Male & 46 & 46.94 \\
\hline & Total & 98 & 100 \\
\hline Age & $18-25$ & 23 & 23.46 \\
\hline & $26-35$ & 45 & 45.92 \\
\hline & $36-45$ & 20 & 20.41 \\
\hline & above 45 & 10 & 10.20 \\
\hline & Total & 98 & 100 \\
\hline Educational level & Read and write & 45 & 45.91 \\
\hline & $1-8$ (primary) & 24 & 24.49 \\
\hline & $9-12$ (secondary) & 15 & 15.31 \\
\hline & Diploma & 9 & 9.18 \\
\hline & Degree & 5 & 5.10 \\
\hline & Total & 98 & 100 \\
\hline Religion & Muslim & 71 & 72.45 \\
\hline & Orthodox & 9 & 9.18 \\
\hline & Protestant & 12 & 12.24 \\
\hline & Catholic & 6 & 6.12 \\
\hline & Total & 98 & 100 \\
\hline
\end{tabular}

Source: Survey conducted 2019.

As clearly stated in the above table (4.1), the respondent profile was examined in terms of sex, age, religion, ethnic group and education level. From the total respondent in terms of sex $53.06 \%$ were females and males were also share $46.94 \%$, this implies that the majority of study participants are females.

The age profiles of the respondents were presented fewer than four categories. The study participants whose are 26-35 share a large than other age group, they share $45.92 \%$ and also shares a large than other age group they share $23.46 \%$ and also next to this respondent with age of $36-45$ share $20.41 \%$. But respondents with the age of $18-25$ shares $23.46 \%$ and respondents also share above the age of 45 , shares $10.20 \%$ from these, it implies that the major participants of the study were from the age of $26-35$. It is $70 \%$ totally also show these age groups within reproductive age. Also they took major contribution in this research finding, even though the study give much emphasize on married individuals than the remain, because there were also an individuals who take family planning before marriage contract.

The study was also seen the educational level of the respondents. From this the majority of respondents were only read and write, they shared $45.91 \%$, this indicated that there is low educational availability it also shared the major than others. There were $5.10 \%$ of respondents who have degree. But 1-8 grade shared 24.49, 912 grade shared $15.31 \%$, Diploma also $9.18 \%$ these all show that there is low education accessibility in Haramaya town of Bate kebele.

The other crucial profile of the respondents were religion, the major study participants in this study were Muslim, its shares $72.45 \%$, the remains were Protestants, Orthodox and Catholic shares $12.24 \%, 9.18 \%$ and $6.12 \%$ respectively. This implies that most respondents of this study have religion, so there religion strongly criticized the taking of family planning services, because most religion in our world does not encourage the taking of family planning services.

\subsection{Perception of Respondents toward Family Planning}

Table 3.2.1. Knowledge of Respondents toward Family Planning

\begin{tabular}{|l|l|l|l|}
\hline Item & Variables & Response \\
\cline { 3 - 4 } & & Infrequency & In percent (\%) \\
\hline knowledge on family planning & & 80 & 81.63 \\
\hline & Yes & 18 & 18.36 \\
\hline & No & 98 & 100 \\
\hline
\end{tabular}

Source: survey conducted 2019 
From the above table (4.2.1), the majority of respondents have knowledge about family planning, $80(81.63 \%)$ of respondents has a knowledge on family planning. But only some respondents have no knowledge about family planning, they share $18(18.36 \%)$ out of the rest. This implies that some respondents have not knowledge, mostly those persons are religions elders man's .But most respondents are not new to the meaning of family planning.

Table 3.2.2. Understanding of Respondents Family Planning

\begin{tabular}{|c|c|c|c|}
\hline Item & Response & In number & In percentage \\
\hline \multirow{4}{*}{$\begin{array}{l}\text { How Understanding family } \\
\text { planning? }\end{array}$} & Limiting number of children & 40 & 40.82 \\
\hline & Taking birth control & 54 & 55.10 \\
\hline & Others & 4 & 4.08 \\
\hline & Total & 98 & 100 \\
\hline \multirow[t]{6}{*}{ Having No. of children } & One & 25 & 25.51 \\
\hline & Two & 30 & 30.61 \\
\hline & Three & 36 & 36.73 \\
\hline & Above & 5 & 5.10 \\
\hline & Have no children & 2 & 2.04 \\
\hline & Total & 98 & 100 \\
\hline \multirow{3}{*}{$\begin{array}{l}\text { Is there free access ability of } \\
\text { family planning service in } \\
\text { your home? }\end{array}$} & Yes & 30 & 30.61 \\
\hline & No & 68 & 69.39 \\
\hline & Total & 98 & 100 \\
\hline \multirow{4}{*}{$\begin{array}{l}\text { Source of information for } \\
\text { side effect of contraceptive } \\
\text { methods }\end{array}$} & Society & 68 & 69.39 \\
\hline & Clinic & 17 & 17.35 \\
\hline & Education & 13 & 13.26 \\
\hline & Total & 98 & 100 \\
\hline
\end{tabular}

Source: Survey conducted 2019

According to the above table (4.2.2), (55.10\%) of the respondent response indicated that understanding family planning in term of taking birth control, this implies that half of the respondents are appropriately know and understand family planning. But $(40.82 \%)$ said that family planning is something like limiting a numbers of children's; this indicated that there are persons who have misconception of family planning services. Also some respondents who said out of the two, they shared $4.08 \%$. From respondent's having three children share more value $36.73 \%$ and having one , two , above three and have no children shares $25.51 \%, 30.61 \%, 5.10 \%$ and $2.04 \%$ respectively. Most respondents respond around $69.39 \%$ can't got free accessibility of family planning service near their home but some respondents respond got free accessibility those shares $30.61 \%$. Respondents have got source of information for different side effect of specific contraceptive methods shares $69.39 \%, 17.35 \%$ and $13.26 \%$ from Society, Clinic and Education respectively.

Table 3.2.3. Information of Respondents toward Family planning

\begin{tabular}{|c|c|c|c|}
\hline \multirow[t]{2}{*}{ Item } & \multirow[t]{2}{*}{ Variables } & \multicolumn{2}{|l|}{ Response } \\
\hline & & Infrequency & In percent \\
\hline \multirow[t]{5}{*}{ Who should have information about family planning } & Husband & 12 & 12.24 \\
\hline & Wife & 20 & 20.41 \\
\hline & Both & 60 & 61.22 \\
\hline & No one & 6 & 6.12 \\
\hline & Total & 98 & 100 \\
\hline \multirow[t]{5}{*}{ Your age at the time of marriage? } & 15 years & 12 & 12.24 \\
\hline & $16-17$ & 26 & 26.53 \\
\hline & $18-22$ & 40 & 40.82 \\
\hline & Above 22 & 20 & 20.41 \\
\hline & Total & 98 & 100 \\
\hline
\end{tabular}

Source: survey conducted 2019

As shown the above table (4.2.3), both husband and wife have more information about family planning, $61.22 \%$ both knows detail about family planning. But only wife who has information about family planning services, they shared $20.41 \%$. Therefore, this implies that there is husband does not have more information about family planning services in Haramaya town of Bate kebele also, there is women's who take the services without 
the known of her husband.

Also there is some husband who have information about family planning services in Bate kebele, they shared $12.24 \%$ implies that some husband have information about the services without known of his wives. However, some respondents totally have not information about family planning they shared $6.12 \%$ out of the rest, this indicated that some respondents whose age above 45 (especially olds) have no information about family planning, because they are strongly attached with religion and traditional believes. From the above table respondents got marriage at the age of between $18-22$ years covers $40.82 \%$ but also there were got marriage under 18 years old this is another impact for various social and health problems.

Table 3.2.4. Males on Using of Family Planning Services

\begin{tabular}{|l|l|l|l|}
\hline Item & Variables & Response & Response \\
\cline { 3 - 4 } & & In number & In percentage \\
\hline $\begin{array}{l}\text { Did males use family planning services like } \\
\text { wives }\end{array}$ & Yes & 12 & 12.24 \\
\hline & & & \\
\hline & No & 76 & 87.76 \\
\hline
\end{tabular}

Source: survey conducted 2019

From the above table (4.2.4), most men's are not taking family planning service like their wives, $(87.76 \%)$ of the respondents did not take the services. So, this implies that there is a misconception toward family planning services that linked to women's. But there are some male respondents who use the services in appropriate manner $(12.24 \%)$, this implies that some males know the use of family planning services.

Table 3.2.5. Decided the Use of Family Planning Services

\begin{tabular}{|c|c|c|c|}
\hline \multirow[t]{3}{*}{ Item } & \multirow[t]{3}{*}{ Variables } & \multirow[t]{2}{*}{ Response } & \multirow[b]{2}{*}{ Response } \\
\hline & & & \\
\hline & & In number & In percentage \\
\hline \multirow{5}{*}{$\begin{array}{l}\text { Who do you think decided about the use of } \\
\text { family planning service? }\end{array}$} & husbands & 12 & 12.24 \\
\hline & Wife & 25 & 25.51 \\
\hline & Both & 58 & 59.18 \\
\hline & no one & 3 & 3.06 \\
\hline & Total & 98 & 100 \\
\hline \multirow[t]{4}{*}{ Economic level of your family } & Low income & 64 & 65.31 \\
\hline & Middle income & 24 & 24.49 \\
\hline & High income & 10 & 10.20 \\
\hline & Total & 98 & 100 \\
\hline
\end{tabular}

Source: survey conducted 2019

According to the above table (4.25), both are decided about the use of family planning services, it covered $59.18 \%$, this indicated that both husband and wife are know and decided about the use of the services. But (25.51) of wives are know about the use of the services, this implies that only some wives know about the use of family planning services, but there husband are no know its function. And also there are husband who are know about the use of family planning, it covers (12.24\%). And also there are respondents who are not know about it use, $(3.06 \%)$ covers by them, this indicated that strongly with in social and cultural beliefs are influences on family planning services utilization. Other important issue is the economic level of the respondent shares $65.31 \%$, $24.49 \%$ and $10.20 \%$ for low, medium and high level of income respectively.

Table 3.2.6. Husband on Family Planning Services

\begin{tabular}{|l|l|l|l|}
\hline Item & Variables & Response & Response \\
\cline { 3 - 4 } & & In number & In percentage \\
\hline $\begin{array}{l}\text { Do you think husband support his wife to the take of family } \\
\text { planning? }\end{array}$ & Yes & 58 & 59.18 \\
\hline & No & 40 & 40.82 \\
\hline & Total & 98 & 100 \\
\hline
\end{tabular}

Source: survey conducted 2019

According to the above table (4.2.6), (59.18\%) of male respondents support there wife to taking of family planning services this indicated that both couples know the use of the services. There are also respondents who reject their wives on the taking of family planning services, its shares $40.82 \%$, this implies that respondents who 
criticized their wives that person are mostly religious men's and highly attached with socio cultural believes.

\section{Conclusion and Recommendation}

\subsection{Conclusion}

According to the finding of this study the following information concerning what were the socio-cultural factors that affect the utilization of family planning services was identifies and what type of attitudes society do have toward family planning was documented.

Family planning challenged by tradition it means the main stream culture toward family planning, society perception, society perceive the concept family planning in a negative sense, it lead to imbalance of ministration, un able to born children to the future, over fatty and other negative explain are given to the services. As clearly stated in the finding of the study, low spousal communication and patriarchal thinking also dominated. All of these things come from the past history of our parents.

Religion also impacted on using of family planning. This by itself leads individuals not to use contraceptives, because, if you are taking the services, the religious leaders sign you as a non-religion and labeled you as evil. Because most religion in our world does not encourage the taking of family planning services.

In addition to these, there are many health care organizations working on the mitigating of socio-cultural factors on family planning. As researcher tried to state in the finding, these health care organizations are not strongly correlated each other in the mitigating of socio-cultural factors on family planning for the maintaining of family planning service in a communities.

To sum up, socio-cultural factors on family planning are existed in a society, they hindered to the taking of the services. There are many misconceptions toward family planning services within a society such as, religion, culture and fearing the side effect. There are also health care institutions that are worked on the maintaining of family planning services.

\subsection{Recommendation}

Based on the finding the recommendations were the following;

$>$ Awareness should be raised by health professionals about the importance of family planning services on family life to each house holders.

$>$ Both governmental and non-governmental health care institutions strongly attach each other for the mitigating of socio-cultural factors affecting on family planning services utilization.

$>$ As the community accepts the preaching of religious leaders, the health extension works should make good communication with them.

$>$ Government strongly linked with community members and remove unnecessary cultural values that affecting the utilization family planning services

\section{Acknowledgments}

I would like to thank Haramaya University College of social science and humanities department of sociology head and Bate kebele Administrative head who support me during the survey work.

\section{References}

Bekele A. (2006). Awareness and determinate of family planning practice in Jimma, Ethiopia, 53 (4): 269-76.

Cleland, J, G, NdogulaR.\& zulu E m, (2011). Family planning in sub-saharan Africa, progress of stage nation total population. Bulleline of WHO 89 (2) 137-143: 10, 247/BLP. 10. 077925.

Fasil H/G., (2006). Knowledge, attitude, decision making for modern contraception in amhara region, north shoa zone. Ethiopia.

Tilahun, T., \&, kassahun, W. (2013). Family planning knowledge, attitude and practice among married women couple in jimma, Ethiopia. 8(4).

USAID., (2008). Ethiopian family planning and reproductive health project final report Weldegerima, B. and Denekew, A., (2008).

Smith R, Ashford L, Gribble J, Clifton D., (2009) Family Planning Saves Life. Population Reference Bureau, USA, pp. 1-25.

Cleland J, Bernstein S, Ezeh A, Faundes A, Glasier A, et al. (2006) Family planning: the unfinished agenda. Lancet 368: 1810-1827.

Gordon C, Sabates R, Bond R, Wubshet T., (2011). Women's education and modern contraceptive use in Ethiopia. International Journal of Education.

Yohannes S, Wondafrash M, Abera M, Girma E. (2011). Duration and determinants of birth interval among women of child bearing age in Southern Ethiopia. 